Original Research Article

\title{
Prescribing pattern of antimicrobial agents in intensive care unit of a teaching hospital in Central India
}

\author{
Sanjay Gedam*, Ajit Pratap Singh, Namita Barmaiya
}

Netaji Subhash Chandra Bose Medical College, Jabalpur, Madhya Pradesh, India

Received: 10 April 2017

Accepted: 06 May 2017

\section{*Correspondence to:}

Dr. Sanjay Gedam,

Email: dr_gedamsanjay@ yahoo.com

Copyright: (C) the author(s), publisher and licensee Medip Academy. This is an openaccess article distributed under the terms of the Creative Commons Attribution NonCommercial License, which permits unrestricted noncommercial use, distribution, and reproduction in any medium, provided the original work is properly cited.

\begin{abstract}
Background: Patients admitted to the Intensive care unit (ICU) receive multiple medications from a variety of pharmacological classes due to various life threatening illness and co-morbidities. The present study aims to evaluate the current usage of anti-microbial agents (AMAs) in the ICU of a teaching hospital in central India.

Methods: A prospective observational study was carried out at the 11 bedded medical ICU of R. D. Gardi Medical College and Hospital, Ujjain (M.P.) for a period of 3 months from Aug 2012 to Oct 2012. The relevant data on drug prescription of each patients was collected from the inpatient case record. The demographic data, disease data and the utilization of different AMAs were analyzed.

Results: A total of 1671 drugs out of which 343 AMAs were prescribed in 148 patients (male-78, female-70) studied, that is, an average of 11.3drugs/patients and 2.32 AMAs/patients. In ICU cefotaxime was the most commonly used AMAs in $17.5 \%$ patients, followed by metronidazole in $14 \%$ patients and ciprofloxacin in $8.8 \%$ patients. Most common indication for the anti-microbial therapy was infection (51.4\%). 80.4\% patients were given 1-3 AMAs, $19.6 \%$ patients were given 4-9 AMAs. amoxicillin+clavulanic acid was the most common FDC noticed.

Conclusions: Interventional programme should focus on infection control with rational antibiotic prescription aimed at minimizing unnecessary cost, adverse drug reaction and emergence of bacterial resistance.
\end{abstract}

Keywords: Antimicrobial agents, Intensive care unit, Prescribing pattern

\section{INTRODUCTION}

Patients admitted to the Intensive care unit (ICU) receive multiple medications from a variety of pharmacological classes due to various life threatening illness and comorbidities.Antibiotics are the most frequently prescribed drugs among hospitalized patients especially in intensive care units. ${ }^{1}$ Indiscriminate and excessive use of antimicrobial agents (AMAs) promotes the emergence of antibiotic-resistant organisms. ${ }^{2-4}$ Antimicrobial resistance substantially raises already-rising health care costs and increases patients morbidity and mortality. ${ }^{5}$ Limited availability of newer agents emphasizes the urgent need for vigilant surveillance, stringent infection control practices, as well as rational antibiotics prescription. ${ }^{6,7}$
The present study aims to evaluate the current usage of anti-microbial agents (AMAs) in the intensive care unit (ICU) of a tertiary care hospital in Ujjain, India.

\section{METHODS}

A prospective, observational study was conducted in 13 bedded ICU of R. D. Gardi Medical College and Hospital, Ujjain over a period of three months from August to October 2012.

The demographic and treatment data were collected in the following format:

- $\quad$ Age and sex of patients

- Diagnosis of patients 
- No. of drugs and AMAs prescribed

- Doses form, dose and route of AMAs

The relevant data on drug prescription of each patients was collected from the inpatient case record. The demographic data, disease data and the utilization of different AMAs were analyzed.

The AMAs were classified according to anatomical therapeutic chemical (ATC) coding system given by WHO.

\section{RESULTS}

In a period of 3 months from Aug 2012 to Oct 2012, Total 204 patients admitted in ICU out of which148 patients were prescribed AMAs. A total of 1671 drugs out of which 343 AMAs were prescribed in 148 patients.

Table 1: Prescribing indicators.

\begin{tabular}{|ll|}
\hline $\begin{array}{l}\text { Total No of Patients Admitted } \\
\text { in ICU }\end{array}$ & 204 \\
\hline $\begin{array}{l}\text { Total No of Patients in which } \\
\text { AMAs prescribed }\end{array}$ & $148(72.55 \%)$ \\
\hline Total No of AMAs prescribed & 343 \\
\hline $\begin{array}{l}\text { Average No of AMAs per } \\
\text { patients }\end{array}$ & 2.32 \\
\hline $\begin{array}{l}\text { Maximum No of Drug is } \\
\text { administered by }\end{array}$ & $\begin{array}{l}\text { Parentral Route } \\
(81.63 \%)\end{array}$ \\
\hline $\begin{array}{l}\text { Maximum No of Drug is } \\
\text { prescribed by }\end{array}$ & $\begin{array}{l}\text { Branded Name } \\
(82.76 \%)\end{array}$ \\
\hline $\begin{array}{l}\text { No of prescription containing } \\
\text { FDCs }\end{array}$ & 42 \\
\hline
\end{tabular}

Table 2: Age and sex wise distribution of patients.

\begin{tabular}{|lll|}
\hline Age in years & Male & Female \\
\hline$<18$ & 1 & 2 \\
\hline $18-30$ & 7 & 16 \\
\hline $31-45$ & 19 & 16 \\
\hline $46-60$ & 29 & 19 \\
\hline$>60$ & 22 & 17 \\
\hline Total & 78 & 70 \\
\hline
\end{tabular}

Table 3: Percentages of most commonly prescribed AMAs.

\begin{tabular}{|ll|}
\hline AMAs & Percentage (\%) \\
\hline Cefotaxime & 17.5 \\
\hline Metronidazole & 14 \\
\hline Ciprofloxacin & 8.8 \\
\hline Ceftriaxone & 7.6 \\
\hline Amoxicillin + Clavulanic Acid & 6.1 \\
\hline Gentamicin & 5.24 \\
\hline
\end{tabular}

In total 148 patients 78 were male and 70 were female. Maximum number of AMAs were prescribed in middle age and elderly population.

Cefotaxime is most commonly prescribed AMA (17.5\%) followed by Metronidazole (14\%).

Table 4: Percentages of most commonly prescribed antimicrobial groups (ATC).

\begin{tabular}{|lll|}
\hline Antimicrobial Groups & ATC & Percentage (\%) \\
\hline $\begin{array}{l}3^{\text {rd }} \text { Generation } \\
\text { cephalosporins }\end{array}$ & J01DD & 25.1 \\
\hline Imidazole derivatives & J01XD & 14 \\
\hline Fluoroquinolones & J01MA & 8.8 \\
\hline$\beta$ lactam antibiotics & J01CR & 6.1 \\
\hline Aminoglycosides & J01GB & 5.24 \\
\hline
\end{tabular}

$3^{\text {rd }}$ generation cephalosporins are most commonly prescribed antimicrobial group $(25.1 \%)$ followed by Imidazole derivatives (14\%).

Table 5: No. of antimicrobial agents per patients.

\begin{tabular}{|ll|}
\hline No of AMAs & Percentage (\%) \\
\hline 1 AMA & 37.84 \\
\hline 2 AMAs & 25.67 \\
\hline 3 AMAs & 16.89 \\
\hline 4 AMAs & 11.49 \\
\hline 5-9 AMAs & 8.1 \\
\hline
\end{tabular}

Maximum no of patients $37.84 \%$ were on 1 AMA and $25.67 \%$ patients were on 2 AMAs.

Table 6: Main diagnosis-patients prescribe AMAs.

\begin{tabular}{|ll|}
\hline Diagnosis & $\begin{array}{l}\text { Percentage of } \\
\text { prescribe AMAs }\end{array}$ \\
\hline $\begin{array}{l}\text { Cardiovascular Diseases along with } \\
\text { sepsis \& multi organ dysfunction }\end{array}$ & 51.35 \\
\hline Respiratory Disease & 17.57 \\
\hline G I Infections & 14.18 \\
\hline Diabetes Mellitus & 10.81 \\
\hline Renal Failure & 8.1 \\
\hline Neurological Disorders & 8.1 \\
\hline UTI & 5 \\
\hline
\end{tabular}

Maximum number of AMAs were prescribed for Cardiovascular diseases along with signs of sepsis and multi organ dysfunction $(51.35 \%)$ followed by respiratory diseases $(17.57 \%)$.

\section{DISCUSSION}

In a period of 3 months 204 patients admitted in ICU out of which 148 patients included in study in whom AMAs were prescribed. A total of 1671 drugs out of which 343 AMAs were prescribed in these 148 patients. Most of the 
patients belongs to middle aged and elderly age group. Our results are approximately same as seen in drug use pattern study in ICU of Northern India, where the average age of patient studied was 49 years. ${ }^{8}$ Similarly, drug use patterns study from an ICU in Iran, the average age of patients studied was 50 years. ${ }^{9}$

In our study Cefotaxime is most commonly prescribed AMA (17.5\%) followed by Metronidazole (14\%) and Ciprofloxacin (8.8\%). Among AMAs group $3^{\text {rd }}$ generation cephalosporins are most commonly prescribed Antimicrobial group (25.1\%) followed by Imidazole derivatives (14\%) and Fluoroquinolones (8.8\%). Drug use pattern study from an ICU in Northern India, the most frequently prescribed antibiotics were found to be 3 rd generation cephalosporins followed by metronidazole and levofloxacin) and other data reported that in India, the most frequently prescribed antibiotic was metronidazole followed by cefotaxime, amoxycillin/ clavulinic acid, cefipime, and ciprofloxacin. ${ }^{8,10}$

In our study, average No of AMAs per patients is 2.32 was similar to that described in other studies. ${ }^{11}$ In our study maximum no of patients $37.84 \%$ were on 1 AMA and $25.67 \%$ patients were on 2 AMAs. Number of AMA per prescription is quite low which is a good indicator of rational practice to minimize ADRs and hospital cost and extra burden to patients. Drug use pattern study from an ICU in Northern India, most patients $(70 \%)$ received 2 or less antibiotics and $60 \%$ of the patients studied in a Caribbean ICU received two antimicrobials. ${ }^{8,12}$ But in our study some $(8.1 \%)$ patients were prescribed 5-9 AMAs which is questionable.

In our study in ICU patients maximum number of AMAs were prescribed for Cardiovascular diseases along with signs of septicaemia and multi organ dysfunction $(51.35 \%)$ followed by Respiratory Diseases $(17.57 \%)$. Most AMAs were prescribed for prevention as well as for treatment of infections.

The common indication for use of antibiotics in our study was treatment and prophylaxis of infection (92.19\%) followed by symptomatic $(11.81 \%)$. This is comparable to the result given by Vandana $\mathrm{AB}$ et al and Pandiamunian J. ${ }^{13,14}$

Most of the patients included in this study were discharged from the ICU after recovery $(74.32 \%)$, while $18.24 \%$ patients expired and $7.43 \%$ patients were absconded.

\section{Limitations}

- Duration of study is three months only.

- Study also did not consider the prescription pattern at seasonal variation of disease.

- Cost analysis has not been carried out because most of the medications are provided by college free of cost to all patients.

\section{CONCLUSION}

Antibiotics are widely prescribed in critically ill patients and form a significant proportion of the total drugs consumed in the ICU. The elderly and sicker patients are prescribed more antibiotics in ICU. The high utilization rates antibiotics prescribed in the ICU are a matter of great concern and need to be evaluated. There is a urgent need to formulate rational antibiotic prescription policy and their strict implementation to prevent indiscriminate use of antibiotics. Interventional programme should focus on infection control with rational antibiotic prescription aimed at minimizing unnecessary cost, adverse drug reaction and emergence of bacterial resistance.

Funding: No funding sources

Conflict of interest: None declared

Ethical approval: Not required

\section{REFERENCES}

1. Krivoy N, El-Ahal WA, Bar-Lavie Y, Haddad S. Antibiotic prescription and cost patterns in a general intensive care unit. Pharmacy Practice. 2007;5(2):6773.

2. Niederman MS. Appropriate use of antimicrobial agents: challenges and strategies for improvement. Crit Care Med. 2003 Feb;31(2):608-16.

3. Kollef MH. Optimizing antibiotic therapy in the intensive care unit setting. Crit Care. 2001;5:189-95.

4. Pulcine C, Pradier C, Samat-Long C, Hyvernat H. J Antimicrob Chemother. 2006;57:546-50.

5. Bassetti M, Di Biagio A, Rebesco B, Amalfitano ME, Topal J, Bassetti D. The effect of formulary restriction in the use of antibiotics in an Italian hospital. Eur J Clin Pharmacol. 2001;57:529-34.

6. Esposito S, Leone S. Antimicrobial treatment of Intensive Care Unit (ICU) infections including the role of the infectious diseases specialist. Int $\mathrm{J}$ Antimicrob Agents. 2007;29:494-500.

7. Lockhart SR, Abramson MA, Beekman SE, Gallagher G, Riedel SR, Diekma D J, et al. Antimicrobial Resistance among gram negative bacilli as causes of Infections in ICU patients in the United States between 1993 and 2004. J Clin Microbiol. 2007;45:3352-9.

8. Williams A, Mathai AS, Phillips AS. Antibiotic prescription patterns at admission into a tertiary level intensive care unit in Northen India. J Pharm Bioall. Sci. 2011;3:531-6.

9. Tavallaee M, Fahimi F, Kiani S. Drug-use patterns in an intensive care unit of a hospital in Iran: An observational prospective study. Int J Pharm Pract. 2010;18:370- 6 .

10. Biswal S, Mishra P, Malhotra S, Puri GD, Pandhi P. Drug Utilization Pattern in the intensive care unit of a tertiary care hospital. J Clin Pharmacol. 2006;46:94551.

11. Hanssens Y, Ismaeil BB, Kamha AA, Elshafie SS, Adheir FS, Saleh TM, et al. Antibiotic prescription 
pattern in a medical Intensive care unit in Qatar. Saudi Med J. 2005;26:1269-76.

12. Hariharan S, Pillai G, McIntosh D, Bhanji Z, Culmer L, Harper-McIntosh K. Prescribing patterns and utilization of antimicrobial drugs in a tertiary care teaching hospital of a Caribbean developing country. Fundam Clin Pharmacol. 2009;23:609-15.

13. Vandana AB, Sanjaykumar BN. study of prescribing pattern of antimicrobial agents in medicine intensive care unit of a teaching hospital in central india. JAPI. 2012 april;60:20-3.
14. Pandiamunian J, Somasundaram G. A study of prescribing pattern of Antimicrobial agents in the medical intensive care unit of a tertiary care teaching hospital in Puducherry union territory south India. Int J Pharm Pharm Sci. 2014;6(3):235-8.

Cite this article as: Gedam S, Singh AP, Barmaiya N. Prescribing pattern of antimicrobial agents in intensive care unit of a teaching hospital in Central India. Int J Basic Clin Pharmacol 2017;6:1507-10. 